\title{
Real Life Leader in the Mirror: An Online Undergraduate Leadership Course Assignment
}

\author{
Dr. Summer Odom \\ Associate Professor \\ Department of Agricultural Leadership, Education, \& Communications \\ Texas A\&M University \\ Valerie McKee \\ Leadership Programs Coordinator \\ IFAS Center for Leadership \\ University of Florida
}

\begin{abstract}
There has been an increased frequency of leadership courses being taught online. Scant research exists that describes effective practices for teaching leadership online. This application brief describes an assignment, the "Real Life Leader in the Mirror" given to undergraduate students in an online personal leadership course as an end of course final project. In this assignment, students synthesize leadership concepts by comparing and contrasting their personalities, interests, beliefs, and capacities with a leader in the media. Through this assignment, students demonstrated the leadership competency of self-awareness and development. Specifically, students articulated knowledge of self, an understanding of self, the value of understanding self, ability to understand self, and the behavior of actually enhancing their understanding of self through this assignment.
\end{abstract}

\section{Introduction}

Interest in teaching leadership online is growing. According to the International Leadership Association (ILA) Directory of Leadership Programs, more than half of the leadership programs that exist offer hybrid (blended) or solely online courses or degree programs. Teaching leadership online can be a challenge. Research on the effectiveness of teaching leadership courses online is scant and the research on the effectiveness of learning online is often conflicting. In a meta-analysis of the empirical literature comparing distance education to traditional classroom instruction, Bernard et al. (2004) found wide variability among measures of achievement, attitude, and retention among the teaching approaches. Some studies indicate differences in learning among distance delivered courses and traditional classroom courses (Davies \& Graff, 2005; Koedinger, Kim, Zhuxin Jia, McLaughlin, \& Bier, 2015; Manning-Ouellette \& Black, 2017). Manning-Ouellette and Black (2017) found that students in online courses may engage more often in deeper learning on assignments. Recent research by Jenkins (2016) found discussion-based pedagogies, reflection, case studies, and group or individual projects were used most frequently by leadership educators in teaching leadership online. While we know little about the effects or outcomes of these online pedagogies on student learning of leadership, research has shown that when educators utilize face-to-face 
methods where instruction occurs experientially, informally, and incidentally, students retain more leadership concepts (Williams \& McClure, 2010).

Based on literature in general about teaching online, online instructors may be held to a higher standard of engagement with their students. Social presence and demonstrated immediacy can influence student satisfaction in online learning environments, and the lack thereof can lead to decreased student satisfaction, motivation, and perceived levels of overall learning (Richardson \& Swan, 2003). Social presence is defined as "the degree of salience of the other person in the (mediated) interaction and the consequent salience of the interpersonal relationships" (Short, Williams, \& Christie, 1976). Some studies suggest that social presence and interactions between the instructor and students contribute to online learning effectiveness (Ally, 2014; Davies \& Graff, 2005; Lehamn \& Conceicao, 2014; McLaren, 2004; Swan, 2001). An instructor's “actions or inaction inform students' perceptions of faulty commitment and authenticity and, ultimately, students' perceived learning experience” (Downing, 2016, p. 178). Thus, the assignments and curriculum plans designed by online educators must be intentional in how they engage students with the instructor and the course material.

Outside of the classroom, students are consumed with a variety of sensory experiences at the touch of their fingertips. Social media, online video games, web-based movie collections, YouTube videos, and other forms of online entertainment can pose as enticing obstacles to overcome for the online learner. As online learning environments become a norm in higher education, it is crucial for leadership educators to innovate new ways to engage students in the leadership development process from the other side of the computer screen. More so, leadership educators have the opportunity to turn the very obstacles that may prevent their students from engaging deeper in course material into helpful, innovative tools for the learning experience.

The opportunity for students to connect class material to examples seen outside of the classroom in their lives or the outer world can provide students with the aptitude to better comprehend, retain, and engage in the material being taught (Bach, 2011; Berk, 2009). Furthermore, the opportunity to utilize pop culture mediums for learning "can create authentic, meaningful and transformative teaching encounters with students of all levels" (Bach, 2011, p. 144). There is unlimited potential in how students may contextually apply course topics, especially in an online learning environment where the internet is at hand for discovering topic application.

Outcomes of leadership education for students are vast. Seemiller (2014) identified eight categories of student leadership competencies. One of these competencies is self-awareness. Self-awareness is a key component of interpersonal leadership development, and "is vital to effective leadership" (Seemiller, 2014, p. 23). While college students enter the process of selfawareness as they move through the vectors of identity development (Chickering \& Reisser, 1993), collegiate leadership educators may capitalize on this process through intentionally designed coursework and facilitation. For students to become self-aware and identify their values, vision, and personal qualities, it is necessary to provide an open, reflective, and creative learning environment (Pennington, 2006). Reflection has been shown to develop greater selfawareness for college students (White \& Guthrie, 2016). And, reflection about a learning activity reveals how students have developed self-awareness (Scott, Whiddon, Brown, \& Weeks, 2015). 
One identified research priority area from the National Leadership Education Research Agenda (NLERA) includes Teaching, Learning, and Curriculum Development with one specific outcome to "Explore curriculum development frameworks to enhance the leadership education transfer of learning" (Andenoro et al., 2013, p. 1). Hence, this application brief has the following objectives: 1) introduce an assignment used in an online personal leadership course and 2) demonstrate how the assignment helps students gain leadership competencies in self-awareness and development. This assignment has been utilized four times in an online undergraduate personal leadership course. The online undergraduate personal leadership course is a course offered as an option to students enrolled in a mostly face-to-face leadership degree program at a large, public university. The course is offered both face-to-face and online in most semesters so students can choose their preferred method of instruction.

\section{Review of Related Scholarship}

Day, Harrison, and Halpin's (2009) theory of leadership development provides a pyramid model combining adult development, leader development, and leader learning. At the top of the pyramid model are the observable aspects of a leader's development, including the acquisition of skills and competencies. While many leadership development efforts are focused on this observable level, these aspects reside on the broad foundation of a person's identity development and their understanding of leadership (Day et al., 2009). According to Day et al. (2009), as a leader's identity becomes more crystallized, it is more likely that the leader will seek out experiences to enact and develop aspects of themselves. One study found that "a high selfawareness score was the strongest predictor of overall success of a leader" (Flaum, 2009, p. 4).

Competencies are defined as the "knowledge, values, abilities, and behaviors that help an individual contribute to or successfully engage in a role or task" (Seemiller, 2014, p. xv). Seemiller (2014) created a list of leadership competencies as a measure for learning outcomes for academic leadership programs. The Student Leadership Competencies consist of sixty competency areas within eight categories; each of the sixty competency areas includes at least four competencies that reflect each of the following dimensions: knowledge of or an understanding of the value of a competency, value placed on a competency, ability to perform a behavior or skill, and behavior engagement. The eight categories include:

1)learning and reasoning,

2) self-awareness and development

3) group dynamics

4) personal behavior

5) civic responsibility

6) strategic planning

7) communication, and

8) interpersonal interaction

Seemiller's (2014) competency category of self-awareness and development will be utilized as a conceptual framework for this application brief. In the category of self-awareness and development, the competencies included are: understands oneself (knowledge), values understanding oneself (value), motivated to enhance the understanding of oneself (ability), and 
enhances the understanding of oneself (behavior). Understanding oneself refers to being aware of your personality, beliefs, capacities, and interests. Values understanding oneself is the belief that "it is important to be aware of one's own personality, beliefs, capacities, and interests in an effort to engage in more authentic and productive behavior" (Seemiller, 2014, p. 24). The competency of being motivated to enhance the understanding of oneself is having the motivation to enhance one's understanding of their personality, beliefs, capacities, and interests so that they can develop a greater understanding of themselves and engage in more authentic and productive behavior. Finally, the competency of enhancing the understanding of oneself refers to actually engaging in behaviors to understand their personality, beliefs, capacities, and interests.

\section{Description of the Practice}

This application brief describes an assignment named "Real Life Leader in the Mirror" given in an online personal leadership course to help students synthesize their self-awareness and development as a leader. The personal leadership course is a junior/senior level course and is required for students completing a major or minor in leadership at a four-year public university. The course is offered both online and face-to-face and students can elect to take the format of their preference based on availability. Students are mostly traditional, on-campus students in a web-based course with the exception of those students taking it in the summer semesters as most of these students are working or completing internships away from campus. The objectives for this course are:

1) Become more aware of, apply, and reflect upon interpersonal and intrapersonal leadership capacities through assessments

2) Articulate a personal leadership vision that is authentic to individual

3) Articulate personal leadership capacities and the implications for use in future leadership roles

4) Demonstrate written and oral communication skills

Assessment in the course consists of two exams, which comprise $40 \%$ of the course, a leadership vision assignment (10\% of the course), module assessments (reflections on weekly content), which comprises $35 \%$ of the course, and the assignment focused on in this application brief (15\%). The assignment was completed at the end of the course. For the "Real Life Leader in the Mirror" assignment, students were asked to think of a leader in the media that is similar to themselves individually. The leader chosen had to be someone who students could easily search for in the media (Internet, book, articles, television, etc.) and find background information on to help them assess some personal characteristics about this leader. Students were asked to describe how they and this leader are similar in characteristics using topics, concepts, and vocabulary learned in the course. Topics in the course included the five practices of exemplary leaders (Kouzes \& Posner, 2014), values development, authentic leadership, strengths, personality type, emotional intelligence, balance, and creativity.

The students were informed they would probably not be able to clearly identify traits and characteristics of the leader in the media. For instance, it is less than likely to find an article listing the leader's strengths or their values or emotional intelligence or way they balance their life. Instead, students were empowered to use the information located about the person and 
make conclusions about the discovered characteristics to complete the assignment. The key to this assignment is for the student to form these conclusions based on the facts and information about the leader. Students were reminded that they may be different from their chosen leaders in some ways. It was acceptable to point out these differences in the written reflection as well.

The assignment outcome was a four-page written reflection describing how the student and the leader share similar interpersonal leadership characteristics. The assignment also required a brief overview of the leader in the written reflection along with the sources used for this information. The overview was to include enough information for the reader to get a general idea of who this person is and what made the student believe the student possesses characteristics in common with this person. Students were assessed on their articulation of the description of the leader, discussion about the similarities of themselves and the leader using proper terminology from the personal leadership course as well as correct APA formatting. Finally, students were assessed on their personal reflections about the leaders including: 1) how the leader they chose is generally viewed by society, 2) whether the students believe they are viewed the same as the leader they chose, and 3) what the students learned about themselves from the assignment.

\section{Discussion of Outcomes}

The assignments from students revealed they gained some leadership competency in the category of self-awareness and development. Students articulated knowledge of self, an understanding of self, the value of understanding self, ability to understand self, and the behavior of actually enhancing their understanding of self.

Understands oneself (knowledge). Students demonstrated they were aware of their personality, beliefs, capacities, and interests through this assignment. This competency was the one most easily assessed through the assignment. Many students chose the topics of personality types, values, strengths, and exemplary leadership behaviors to compare to their chosen leader. They gave examples from their life of how they demonstrate knowledge of personality, beliefs, capacities, and interests through this assignment. Here is a quote from one of the student's assignments:

As an intuitive personality, I feel that I can sense the emotions of other people. I think this intuition helps Diane Sawyer get those she interviews to disclose information to her that they normally may not feel comfortable sharing. Intuitive people also focus on future possibilities, the big picture, and insights. I tend to focus on the future and the big picture when it comes to everything including life, school work, or an organization.

Values understanding oneself (value). Students demonstrated their value of understanding self through this assignment. Though not as easily assessed from this assignment, there was some indication that students believed it was important to know your personality, beliefs, capacities, and interests. Some students discussed how they can now leverage their leadership capacities to be more effective leaders. An example of a student valuing their leadership capacity is shown through this student's quote: "Having communication as a strength is vital in the leadership process." Another student said this: 
Through this assignment I have learned that I am capable of many things. I have become more aware of what I can do if I put my mind to it. If I have some of the same traits of a man that once led our country then what is stopping me from doing that? I have realized that I have the ability to be not only a successful man but a successful leader.

Motivated to enhance the understanding of oneself (ability). Students demonstrated their motivation to understand self as they discussed researching more about their own personality types. Some mentioned that they actually reevaluated what their strengths or personality type meant as they were writing this paper. Some students discussed how the assignment helped them critically evaluate their less preferred aspects of self and now they can use it to improve for future situations. One student said this:

I see Patton and I have similar traits and have learned from researching about him how to better lead the people around me. I would like to better develop my core values and establish a better self-confidence in myself.

Another student reflected:

His actions motivate me personally as a leader. I am honored to be able to find similarities with him [Blake Mycoskie] and his personal visions. His story has helped me in creating a personal goal for myself. I aspire to be a leader like him.

Enhances the understanding of oneself (behavior). Changes in behavior were evident in this assignment as students did actually enhance their understanding of self. Some students remarked that this assignment helped them gain a more clear idea of aspects of their leadership which were helpful and ones that may need improvement. An example of how a student reflection illustrated the understanding of oneself is through this quote:

I have learned that all of my results from the Gallup's Strength Report, Life Values Inventory, and MBTI test results all go more hand-in-hand than I realized. Being able to think of all of these in retrospect of this semester and combining them to match to another leader makes me realize how much they all make one entire picture of me as a leader.

\section{Reflections of the Practitioner}

This assignment "Real Life Leader in the Mirror" seemed to really help students gain self-awareness by looking at themselves through the lens of someone else. Some students remarked at how fun the assignment actually was and that they had not really ever thought of how they compared to other leaders. Leaders chosen for the assignment ranged from war heroes to political leaders to athletes to movie characters. Examples of specific leaders featured in students' assignments included Abraham Lincoln, Dick Cheney, Ellen DeGeneres, Yoda from Star Wars, General Martin Dempsey, J. J. Watt, Oprah Winfrey, and Hillary Clinton.

We believe this assignment was effective at getting students to think differently about themselves and possibly engage deeper with the course content, a conclusion drawn by ManningOuellette and Black (2017) in regards to differences in online versus traditional classroom 
instruction learning. The instructors have taught the course both online and face-to-face. The assignments are different in each of the course instructional formats so there is no data to examine for differences among students in each of the course formats. However, the instructors believe that this assignment allows for students to meet the objectives of the course and apply course concepts in a meaningful way.

\section{Recommendations}

The assignment was very easy to assign. Through an online format, very little instruction was given other than the assignment description and rubric. Students did very well in synthesizing course topics for this assignment. If there was one thing that some students may not have done as well in, it was the articulation of the course concepts. Some students tended to use vague language instead of the terminology from the course when explaining characteristics about themselves and their chosen leader. Leadership practitioners who want to utilize this assignment should reiterate for students the need to connect course concepts by using vocabulary and terminology from course materials and to use proper citations throughout the paper.

\section{References}

Ally, M. (2014). Foundations of educational theory for online learning. In Anderson, T. Elloumi, F. (Eds.), Theory and Practice of Online Learning. Athabasca, AB: Athabasca University.

Andenoro, A. C., Allen, S. J., Haber-Curran, P., Jenkins, D. M., Sowcik, M., Dugan, J. P., \& Osteen, L. (2013). National leadership education research agenda 2013-2018: Providing strategic direction for the field of leadership education.

Bach, J. (2008). A problem-based learning approach based on reality TV? Academic Exchange Quarterly, 12(1), 153-157.

Berk, R.A. (2009). Multimedia teaching with video clips: TV, movies, YouTube, and mtvU in the college classroom. International Journal of Technology in Teaching and Learning, 5(1), 1- 21.

Bernard, R.M., Abrami, P. C., Lou, Y., Borokhovski, E., Wade, A., Wozney, L., Walet, P. A., Fiset, M., Husang, B. (2004). How does distance education compare with classroom instruction? A meta-analysis of the empirical literature. Review of Educational Research, 74(3), 379-439.

Chickering, A. W., \& Reisser, L. (1993). Education and identity (2nd ed.). San Francisco, CA: Jossey-Bass.

Day, D. V., Harrison, M. M., \& Halpin, S. M. (2009). An integrative approach to leader development: Connecting adult development, identity, and expertise. New York: Routledge. 
Davies, J., \& Graff, M. (2005). Performance in e-Learning: Online participation and student grades. British Journal of Educational Technology, 36(4), 657-663.

Downing, M. S. (2016). Authentic classroom leaders: The student perspective. Journal of Leadership Education, 15 (1), 178-180.

Flaum, J. P. (2009). When it comes to business leadership, nice guys finish first. Green Peak Partners Executive Study. Retrieved from: http://greenpeakpartners.com/resources/pdf/6\%208\%2010\%20Executive\%20study\%20G P\%20commentary\%20article_Final.pdf

Jenkins, D. M. (2016). Teaching leadership online: An exploratory study of instructional and assessment strategy use. Journal of Leadership Education, 15(2), 129-149.

Koedinger, K. R., Zhuxin Jia, J., Kim, J., McLaughlin, K. R., Bier, N. L. (2015). Learning is not a spectator sport: Doing is better than watching for learning from a MOOC. Proceedings of the Second ACM Conference on Learning, Canada, 111-120. doi: $10.1145 / 2724660.2724681$

Lehman, R., \& Conceicao, S. (2014). Motivating and retaining online students: Research based strategies that work. San Francisco, CA: Jossey-Bass.

Manning-Ouellette, A., \& Black, K. M. (2017). Learning leadership: A qualitative study on the differences in student learning in online versus traditional courses in a leadership studies program. Journal of Leadership Education, 16(2), 59-79. doi: 1012806/V16/I2/R4

McLaren, C. (2004). A comparison of student persistence and performance in online and classroom business statistics experiences. Decision Sciences, 2(1), 1-10.

Pennington, P. (2006). Authentic leadership in the college classroom. Academic Exchange Quarterly, 10(2), 12-16. Retrieved from http://rapidintellect.com/AEQweb/edchoiceold.htm

Richardson, J. C., \& Swan, K. (2003). Examining social presence in online courses in relation to students' perceived learning and satisfaction. Journal of Asynchronous Learning Networks, 7(1), 68-88.

Scott, M., Whiddon, A. S., Brown, N. R., Weeks, P. P. (2015). The journey to authenticity: An analysis of undergraduate personal development. Journal of Leadership Education, 14(2), 65-81. doi: 1012806/V14/I2/R5

Seemiller, C. (2014). The student leadership competencies guidebook: Designing intentional leadership learning and development. San Francisco, CA: Jossey-Bass. 
Short, J., Williams, E., \& Christie, B. (1976). The social psychology of telecommunications. London: John Wiley and Sons.

Swan, K. (2001). Virtual interaction: Design factors affecting student satisfaction and perceived learning in asynchronous online courses. Distance Education, 22(2), 306-331.

White, J. V., \& Guthrie, K. L. (2016). Creating a meaningful learning environment: Reflection in leadership education. Journal of Leadership Education, 15(1), 60-75, doi: 1012806/V15/I1/R5

Williams, J. R., \& McClure, M. (2010). The effects of teaching methods in leadership knowledge retention: An experimental design of lecture, experiential, and public pedagogy. Journal of Leadership Education, 9(2), 86-100.

\section{Author Biographies}

Summer Odom is an Associate Professor in the Department of Agricultural Leadership, Education, \& Communications at Texas A\&M University. She teaches undergraduate and graduate courses in leadership. Her research interests include leadership capacity building of young adults and assessment and evaluation of leadership pedagogy. Her email is summerodom@tamu.edu.

Valerie McKee is the Leadership Programs Coordinator for the University of Florida Institute for Food and Agriculture Science Center for Leadership. McKee works with stakeholders to develop their leadership capacities through facilitation and program support. McKee is a PhD student studying leadership education at UF. Her email is vmckee@ufl.edu. 